\title{
One Adult Who Is Crazy about You: Can Natural Mentoring Relationships Increase Assets among Young Adults With and Without Foster Care Experience?
}

\author{
Johanna K.P. Greeson ${ }^{\star}$, Lynn Usher, and Michal Grinstein-Weiss \\ University of North Carolina at Chapel Hill, School of Social Work
}

\section{Abstract}

During emerging adulthood, most youth receive family support to help them weather the difficulties associated with transitioning to independence. When foster youth emancipate, they confront the challenges associated with emerging adulthood, and are at risk of having to transition without family support. Many are in danger of failing to meet minimal levels of self-sufficiency. A caring adult who offers social support is normative for adolescent development and protective for youth across many risk conditions. Natural mentoring can cultivate such relationships. This study examines the association between natural mentor relationship characteristics, and material hardship and asset-related outcomes during the emerging adulthood period in both a normative sample of young adults and young adults identified as former foster youth. This study also considers the potential mediating effect of future expectations. Data from Wave 3 of the National Longitudinal Study of Adolescent Health that pertain to 15,197 respondents are used. Path models with categorical dependent variables were estimated using a Maximum Likelihood method with standard errors that are robust to non-normality and non-independence of observations. "Like a parent," "role model," and "guidance/advice" were significantly associated with assets among both groups. This study contributes to the growing body of literature on natural mentoring and former foster youth, and highlights the value of increasing our understanding of natural mentor roles for intervention development. The focus on assets-related outcomes is a novel approach to investigating the benefits of natural mentoring to the healthy development of youth. This paper is the first to consider the association between natural mentoring and assets building among both former and nonformer foster youth.

\section{Keywords}

natural mentoring; assets; future expectations; relationship strength; former foster youth; foster care; individual risk; emerging adulthood; mediation

\footnotetext{
(C) 2009 Elsevier Ltd. All rights reserved.

"Corresponding author: Reprints are available from Johanna K.P. Greeson, School of Social Work, University of North Carolina Chapel Hill, 325 Pittsboro Street, CB \#3550, Suite 400, Chapel Hill, NC 27599-3550; (919) 259-1322; johanna@ johannagreeson.com. Publisher's Disclaimer: This is a PDF file of an unedited manuscript that has been accepted for publication. As a service to our customers we are providing this early version of the manuscript. The manuscript will undergo copyediting, typesetting, and review of the resulting proof before it is published in its final citable form. Please note that during the production process errors may be discovered which could affect the content, and all legal disclaimers that apply to the journal pertain.
} 


\section{Introduction}

In the late 1990s, the Downpayments on the American Dream Policy Demonstration (ADD) was launched by the Corporation for Enterprise Development. ADD was the first large-scale test of Individual Development Accounts, or matched savings accounts for poor people, which are earmarked for homeownership, postsecondary education, and entrepreneurship (Corporation for Enterprise Development, n.d.). Since that time, the understanding that poor people can save, accumulate assets, buy homes, start businesses, and pursue higher education when provided the right incentives and supports has gradually moved to the forefront of our collective awareness. The potential for asset building to contribute to stronger families, stronger neighborhoods, and stronger communities is the backbone of this anti-poverty strategy.

Asset accumulation is an important part of becoming a self-sufficient adult, and typically begins during emerging adulthood, or the transitional period from late adolescence into adulthood. During this time, most youth receive family support that helps smooth the road to independence and set the stage for effective asset building. Yet, youth aging out of foster care are less likely than other young adults to have families on whom they can depend to help them withstand the challenges associated with transitioning to independence. As a result, the likelihood that this at-risk population will be able to build assets, reach life goals, realize their full potential, and contribute to the economy and society is severely diminished.

An impressive body of research on resilience in at-risk youth and the role of supportive adults suggests that a relationship with at least one significant adult who is not a parent leads to improved outcomes (e.g., Garmezy, 1985; Rutter, 1987; Werner \& Smith, 2001). This research is often referred to as the "beating the odds" studies (Rhodes \& Boburg, 2009). Across the board and without regard to location, time, or context, the common element in all the stories of youth who have "beat the odds," is the presence of at least one adult - in addition to parents - who provides guidance and support. Over the years, this type of relationship with a caring adult has been confirmed as not only protective for at-risk youth, but also as a normative component of adolescent development (Beam, Chen, \& Greenberger, 2002).

Using data from Waves 1 and 3 of the National Longitudinal Study of Adolescent Health (Add Health), this study examines the association between caring adult relationships (i.e., natural mentors) and asset-related outcomes during the emerging adulthood period (age 18 25 years) in both a normative sample of young adults and a sample of young adults identified as former foster youth. Comparison to young adults in the general population provides an awareness of how former foster youth are getting by during the transition to adulthood in relation to their peers, and can elucidate similarities and differences between the two groups in the patterns of association between natural mentoring and asset accumulation.

\subsection{Assets-Related Outcomes for Former Foster Youth During Emerging Adulthood}

Mounting evidence suggests that holding assets, including liquid (i.e., savings or checking account) and physical (i.e., home or car) assets may have both short- and long-term positive 
effects on individuals, families, and communities (Dietz \& Haurin, 2003; Page-Adams \& Sherraden, 1997). Building assets is particularly beneficial for individuals who are economically vulnerable, including former foster youth. The increasing body of research on assets building suggests positive effects on personal wellbeing, including increased life satisfaction and self-efficacy, decreased depression and alcohol abuse (Rohe \& Stegman, 1994a; Yadama \& Sherraden, 1996), and improved physical health (Robert \& House, 1996); civic behavior, including increased recycling behavior and involvement in block associations, (Oskamp et al., 1991; Perkins, Florin, Rich, Wandersman, \& Chavis, 1990; Rohe \& Stegman, 1994b) and increased neighborhood reinvestment (Galster, 1987; Van Zandt \& Rohe, 2006); and children's wellbeing, including adolescents' increased selfesteem (Whitbeck et al. 1991), decreased school drop out behavior, increased avoidance of early pregnancy (Green \& White, 1997), and greater likelihood of future home owning of adult children (Henretta, 1984). Given the myriad benefits of holding assets, researchers are now paying increased attention to asset building and ownership as a mechanism to promote individual self-sufficiency and economic security, family wellbeing, and community revitalization.

Former foster youth typically experience an array of material hardships and lack both liquid and physical assets during emerging adulthood (Courtney et al., 2007; Pecora et al., 2006). As early as 1990, Barth documented the self-sufficiency problems experienced by former foster youth. Of the 55 youth interviewed in the San Francisco Bay Area and Sacramento, $47 \%$ had problems paying for food or housing, $35 \%$ were homeless, and $25 \%$ were unemployed. Therefore, it is not surprising that these young people also typically lack assets. These include not having a checking or savings account (Courtney et al., 2007) and not owning a home (Pecora et al., 2004). Yet, to date, few studies have considered assetrelated outcomes among samples of former foster youth. At age 21, only half of the youth in the Midwest Evaluation of the Adult Functioning of Former Foster Youth study reported having a bank account, $3 \%$ reported owning a residence, and only $39 \%$ reported owning a vehicle (Courtney, et al. 2007). To provide some context for these findings, Courtney and colleagues (2007) made comparisons between their sample of young adults who aged out of foster care and a nationally representative sample of 21-year-olds who participated in Add Health. Almost $81 \%$ of the Add Health 21-year-olds reported having a bank account, $9 \%$ reported owning a residence, and $73 \%$ reported owning a vehicle. The homeownership rates for the general population of young adults are much higher. In the first quarter of 2009, 24\% of individuals aged 24 or younger reported owning a residence (U.S. Census Bureau's, 2009).

The only other studies known to the authors to have examined asset-related outcomes are the Casey National Alumni Study (Pecora et al., 2004) and the Northwest Foster Care Alumni Study (Pecora et al., 2005). In the former, only $27 \%$ of the more than a thousand Casey Family Programs foster care alumni reported owning a home. In the later study, of the almost 500 participants, only $9 \%$ reported owing a residence. These percentages are much lower than the $68 \%$ of Americans who owned their own home in 2008 (U.S. Census Bureau, 2008). 
Although evidence on the assets of former foster youth is scant, the Corporation for Enterprise Development recently extended the positive results of the Downpayments on the American Dream Policy Demonstration (ADD) to this vulnerable population by launching the SEED (Saving for Education, Entrepreneurship, and Downpayment) Initiative in 2003. Building on the lesson from ADD that poor people can save, accumulate assets, buy homes, start businesses, and pursue higher education when provided the right incentives and support structures, the SEED Initiative is a 10-year endeavor to develop, test, inform, and promote matched savings accounts and financial education for children and youth. Part of the SEED Initiative is a special foster youth SEED Initiative that is being piloted in Colorado and Oklahoma. At present, there are more than 170 foster youth involved in financial literacy training, who are saving toward asset purchases such as post-secondary education, housing, transportation, and small business development (Rosen, 2007).

Still in its infancy, there are not yet any empirical findings from the foster youth SEED Initiative. However, preliminary lessons have emerged, which support both the wisdom of facilitating asset accumulation for this special population as well as the importance of a relationship with a caring adult for these vulnerable youth. These lessons include (a) the ability of foster youth to save and make wise use of savings incentives; (b) the need for support services for foster youth because of their unique life circumstances; and (c) the necessity for a wider range of eligible uses of accounts to meet the unique needs of this population. The need for support services speaks directly to the critical role of caring adults. The SEED Initiative refers to such help as "high touch," denoting the importance of handson, highly personalized supports to help foster youth succeed in building assets (Rosen, 2007).

Asset accumulation is a significant part of development during emerging adulthood and directly influences the achievement of self-sufficiency as well as other important noneconomic outcomes. Successful navigation of this developmental process may be especially essential for former foster youth who are less likely than other young adults to have families to whom they can turn for financial support in times of need (Courtney et al., 2007). Therefore, developing strategies that help former foster youth build assets and achieve economic independence is of paramount importance.

\subsection{Natural Mentoring and Foster Youth}

Natural mentoring has emerged as one way to cultivate caring relationships between youth and adults and more recently has been recognized as a promising approach for foster youth (Ahrens, DuBois, Richardson, Fan, \& Lozano, 2008; Courtney \& Lyons, 2009) facing emancipation and the transition to adulthood. Theoretically and developmentally, natural mentoring may provide a better fit than other forms of mentoring, such as programmatic. Natural mentoring relationships form gradually and are therefore likely to be less pressured. The natural mentor is familiar to the youth, and as a result, the youth is less likely to have difficulty trusting the adult and developing an enduring bond (Ahrens et al., 2008; Britner, Balcazar, Blechman, Blinn-Pike, \& Larose, 2006). Similarly, both the youth and the natural mentor are already in each other's social networks and are likely to remain there. 
Consequently, the chances that the relationship will continue over time are better, and the likelihood of positive outcomes increases (Hamilton et al., 2006).

Several studies have examined the impact of natural mentors on the lives of former foster youth. Ahrens and colleagues (2008) used data from Add Health to investigate whether youth in foster care with natural mentors during adolescence had improved young adult outcomes $(n=310)$. Mentored participants $(n=160)$ were more likely to report favorable overall health and were less likely to have reported suicidal ideation, to have received received a sexually transmitted infection, and to have hurt someone in a fight in the past year. Similarly, Munson and McMillen (2009) analyzed data from a longitudinal study of older youth transitioning from foster care in Missouri $(n=339)$. Youth in long-term natural mentoring relationships were less likely to have been arrested at age 19 and reported fewer depression symptoms, less stress, and more satisfaction with life.

Most recently, Courtney and Lyons (2009) used data from the Midwest Evaluation of the Adult Functioning of Former Foster Youth (Midwest Study) to examine whether natural mentoring relationships were associated with outcomes at age 21 for former foster youth making the transition to adulthood $(n=590)$. Results showed that closeness to an adult mentor was associated with an increase in the estimated odds of having worked in the past year and a large reduction in the odds of recent homelessness. However, unlike the two previous studies, no association between having a natural mentor and delinquency outcomes (arrests and incarceration) was found.

No research known to the authors has assessed the association between having a natural mentor relationship and accumulation of assets. Yet, based on the limited research available concerning natural mentorship and material hardship, which showed an association between closeness to a natural mentor and increased likelihood of employment and decreased likelihood of homelessness (i.e., Courtney \& Lyons, 2009), a relationship between natural mentorship and assets is plausible.

\subsection{Future Expectations}

Future expectations, or the degree to which individuals have positive attitudes toward their future, including believing that good outcomes are achievable for them and feeling a high degree of control over their futures (Robbins \& Bryan, 2004), is an emerging line of inquiry related to how caring adults may help at-risk youth avoid negative outcomes and achieve positive outcomes (e.g., DuBois \& Silverthorn, 2005). Positive future expectations have been linked to fewer risky behaviors and better young adult outcomes among the general population (Aronowitz, 2005; Somers \& Gizzi, 2001), and to fewer sexual risk behaviors and fewer school behavioral problems in foster youth (Cabrera \& Auslander, 2007). Courtney and colleagues (2007) evaluated former foster youth's orientation toward the future with a set of questions that ask asked them to rate their likelihood of experiencing a particular event. On average, the Midwest youth reported having between "a 50/50 chance" and "some chance, but probably not" of earning a middle-class income by age 30 and more than a middle-class income by age 30 . 


\subsection{Conceptual Framework}

Given the paucity of research on natural mentoring and asset accumulation among former foster youth during the emerging adulthood period, this study makes an important contribution to the natural mentoring evidence base. This study also importantly considers the potential role of future expectations as a mediator in an attempt to identify a possible natural mentoring process. A conceptual model was developed based on the literature related to foster care alumni and natural mentoring, which was used to guide in the formulation of the following questions regarding main effects:

1 Is a natural mentor relationship associated with increased assets at Wave 3?

2 Among youth with a natural mentor, do relationship strength and number of roles filled by a natural mentor predict increased assets at Wave 3?

3 Among youth with a natural mentor, do relationship strength and specific individual roles filled by a natural mentor predict increased assets at Wave 3 ?

In addition, the role of future expectations was examined by asking the following questions about mediating effects:

4 Do future expectations at Wave 3 mediate the relationship between relationship strength and assets at Wave 3 and number of roles and assets at Wave 3?

5 Do future expectations at Wave 3 mediate the relationship between relationship strength and assets at Wave 3 and specific individual roles and assets at Wave 3?

Lastly, the patterns and magnitudes of the structural path coefficients for the former foster youth sample and non-former foster youth sample were evaluated by asking the following question:

6 Do the patterns and magnitudes of the associations between variables differ by sample?

\section{Method}

This study relies on restricted-use data from the National Longitudinal Study of Adolescent Health (Add Health), a cohort study that began in 1994 that explores the causes of healthrelated behaviors of adolescents and their outcomes in young adulthood. Currently in its fourth wave of data collection, the survey seeks to examine how social contexts (families, friends, peers, schools, neighborhoods, and communities) influence adolescents' health and risk behaviors. A sample of 80 high schools and 52 middle schools from the U.S. was selected with unequal probability of selection.

\subsection{Study Design}

This study uses Add Health data from Waves 1 and 3 , when the youth were in $7^{\text {th }}$ to $12^{\text {th }}$ grades, and when they were between the ages of 18 and 26, respectively. Therefore, the Wave 3 sample consists of Wave 1 respondents who could be located and re-interviewed six years later (Harris et al., 2003). Using Add Health as secondary data, this study employs a nonequivalent comparison group design to assess the association between natural mentoring relationship characteristics and assets and material hardship, and to determine whether this 
association is similar across samples of former foster youth and normative youth. The magnitude and mechanism of effects of natural mentoring is compared between young adults with natural mentors that identify themselves as having prior experience in foster care, and a normative sample of young adults with natural mentors (but no foster care experience).

\subsection{Sample}

Data for this study pertain to 15,197 respondents represented in the Wave 3 restricted-use data set. Of these, 14,823 respondents had valid cluster and stratification variables. Of the 14,823 respondents, 8,151 reported having a natural mentor at any time since age 14 .

Respondents who endorsed a younger sibling, friend, or spouse/partner were excluded. Respondents who reported "other" as a natural mentoring role or who were missing an answer to the natural mentorship question were also excluded due to not being able to group them into a social role category. Of the 8,151 respondents with natural mentors, 165 reported at Wave 3 that they had been in foster care (i.e., "Did you ever live in a foster home?"); 7,977 respondents with natural mentors reported that they had not been in foster care; and nine respondents were missing the foster care variable.

The sample characteristics of the young adults included in this study are shown in Table 1. The descriptive statistics are design-based and take into account the complex sample design of the data, including the unequal probability of selection. Therefore, they are generalizable to a population of young adults with natural mentors. Among the former foster youth, more than half of the youths in the sample were female (66\%). Almost all were nonHispanic $(97 \%)$, and $74 \%$ were White. Participants' average age was 21.5 years ( $S D=1.5$ years). Thirty percent completed high school and the majority of youth reported not being married at the time of the interview (75\%). About half (51\%) reported being employed full time. Only $9 \%$ of the participants were receiving public assistance at the time of data collection. Two fifths (40\%) of the sample reported having been placed in more than one foster home during their youth. Only about $1 \%$ of the former foster youth reported owning assets.

Among the nonformer foster youth, about half of the respondents were female (51\%). Almost all were nonHispanic (90\%), and $80 \%$ were White. Participants' average age was 21.3 years $(S D=1.6$ years). Almost half $(47 \%)$ completed some college, and the majority of youth reported not being married at the time of the interview (87\%). Almost half $(46 \%)$ reported being employed full time. Only $4 \%$ of the participants were receiving public assistance at the time of data collection. Most youth reported having a bank account (87\%) and owning a car (72\%). Only $10 \%$ reported owning their residence.

Among the former foster youth, about $25 \%$ reported that their mother was receiving public assistance at Wave 1. Almost half (48\%) had ever received an out-of-school suspension, and $37 \%$ had ever received psychological counseling. The majority (90\%) of youth reported usually feeling safe in their neighborhood. The majority of youth also reported their mothers caring about them very much (90\%) and their friends caring about them very much (90\%).

Among the nonformer foster youth, fewer than 1 in $10(9 \%)$ reported that their mother was receiving public assistance at Wave 1 . About one quarter (23\%) of the nonformer foster 
youth had ever received out-of-school suspension, and $12 \%$ had ever received psychological counseling. The majority $(91 \%)$ of youth reported usually feeling safe in their neighborhood. The majority of youth also reported their mothers caring about them very much $(98 \%)$ and their friends caring about them very much $(87 \%)$.

Among the former foster youth, their natural mentors on average filled slightly more than one role $(S D=.62)$ in their lives. More than half $(56 \%)$ reported having a natural mentor who provided guidance or advice, and more than half (56\%) reported having a natural mentor who provided emotional nurturance. Receiving practical help from a natural mentor was reported by $13 \%$ of the former foster youth. Very few of the former foster youth (1\%) reported having a natural mentor who was like a parent, and $8 \%$ reported having one who was a role model. Only $1 \%$ reported having a "very close" relationship with their natural mentor, and the average duration of the natural mentoring relationship was 10.54 years ( $S D$ $=7.89$ years). For $83 \%$ of the former foster youth, their natural mentors became important in their lives early (between 0 and 17 years). The most common social role filled by the natural mentors was relative (54\%), followed by school personnel (25\%) and community member $(21 \%)$. About half $(53 \%)$ of the former foster youth were introduced to their natural mentors through school. Almost $100 \%$ of the former foster youth reported their natural mentors still being important to them at Wave 3. An almost equal proportion of former foster youth reported seeing their natural mentors at least once per month (55\%) (compared to less than one time per month), and $60 \%$ reported talking to or emailing their natural mentors at least once per month.

Among the nonformer foster youth, their natural mentors on average filled slightly more than one role $(S D=.61)$ in their lives. More than half $(60 \%)$ reported having a natural mentor who provided guidance or advice. Forty percent of the nonformer foster youth reported having a natural mentor who provided emotional nurturance. Receiving practical help from a natural mentor was reported by $10 \%$ of the former foster youth. Very few of the nonformer foster youth had a natural mentor who was "like a parent," and 15\% reported having a mentor who was a "role model." About half reported having a very close relationship with their natural mentor, and the average duration of the natural mentoring relationship was 8.94 years ( $S D=7.07$ years). For a little more than three quarters $(78 \%)$ of the nonformer foster youth, their natural mentors became important in their lives early (between 0 and 17 years). The most common social role filled by the natural mentors was relative (45\%), followed by school personnel (33\%) and community member (22\%).

Slightly more than half (56\%) of the nonformer foster youth were introduced to their natural mentors through school. Almost $100 \%$ of the former foster youth reported their natural mentors still being important to them at Wave 3. Almost equal proportions of nonformer foster youth reported seeing their natural mentors and talking to or emailing their natural mentors at least one timer per month.

\subsubsection{Descriptive Differences Between Former Foster Youth And Nonformer Foster Youth-Chi-square and $t$-tests were conducted to assess differences between the} two groups on the demographic and relationship characteristics as well as on the outcome variables (Table 1). Former foster youth were more likely to be nonHispanic $(p<.05)$ and married $(p<.05)$. At Wave 1 , the mothers of former foster youth were more likely to receive 
welfare $(p<.0001)$. Former foster youth were also more likely to receive out-of school suspension $(p<.0001)$ and psychological counseling $(p<.0001)$ at Wave 1. Former foster youth were more likely to have a natural mentor who provided "emotional nurturance" $(p<$. $01)$.

Nonformer foster youth were more likely to have completed some or all of college $(p<$. 0001). Nonformer foster youth were also more likely to have a bank account $(p<.0001)$ at Wave 3. At Wave 1, nonformer foster youth were more likely to report that their mothers cared about them very much $(p<.001)$. Nonformer foster youth were more likely to have a natural mentor who was "like a parent" $(p<.05)$.

\subsection{Measurement}

2.3.1 Natural Mentorship-The presence or absence of a natural mentor was based on a single retrospective question from Wave 3 . This question asks respondents whether an adult other than a parent/step-parent has made an "important positive difference in your life at any time since you were 14 years old." Participants who reported younger siblings, spouses, friends, or "other" as their natural mentors were excluded (Ahrens et al., 2008; DuBois \& Silverthorn, 2005). This variable was dummy-coded. A code of one represented an answer of "yes" to this question. Zero represented an answer of "no."

2.3.2 Natural Mentor Functional Role-Functional roles filled by natural mentors were determined from a retrospective, open-ended question at Wave 3 that asked the respondents what their natural mentors did to help them. Responses were re-coded into functional role categories: (a) providing guidance and advice, (b) providing emotional support, (c) providing practical help, (d) being like a parent, and (e) serving as a role model. These categories are not mutually exclusive, and are consistent with the social support typology described by House (1981) and used by Greeson and Bowen (2008). The five individual roles and a composite created by summing the number of roles together were used as independent variables.

2.3.3 Natural Mentor Relationship Strength-Relationship strength between the natural mentor and young adult was assessed from a question that asks the respondent, "How close do you feel to him/her these days?" Responses were on a five-point Likert scale of "closeness" ranging from zero ("not close at all") to four ("very close"). Consistent with previous research using these data (i.e., McDonald, Erickson, Johnson, \& Elder, 2007), the responses were re-coded to create a dichotomous variable: "very close" ("very close" and "quite close") and "not so close" ("somewhat close," "only a little close," and "not close at all") and then dummy coded ( $1=$ very close; $0=$ not so close).

2.3.4 Former Foster Youth-Former foster youth status is a dummy variable created from the answer to a single Wave 3 item, "Did you ever live in a foster home?" A code of one represented "yes;" zero represented "no." This operationalization is consistent with previous research that has used the same sample of young adults (i.e., Ahrens et al., 2008).

2.3.5 Assets-Three individual items that consider one's property holdings and basic financial characteristics measured assets. Responses to all items were dichotomous (yes=1/ 
no=0). The items were "Do you own a residence such as a house, condominium, or mobile home?", "Do you own a car, truck, van, or motorcycle?", and "Do you have a bank account (savings and/or checking)?"

2.3.6 Future Expectations-Income expectations served as a proxy for the construct "future expectations," and was an index created by averaging the two income items from six personal future items in Add Health: "Chance of middle class income at age 30" and "Chance of more than a middle class income at age 30." Responses were on a five-point Likert scale of "certainty" ranging from one ("almost certain") to five ("almost no chance"). Because of this counter-intuitive response pattern, the variable was recoded such that a higher index value is indicative of greater income expectations, and a lower index value is indicative of poorer income expectations.

2.3.7 Covariates-Covariates were selected based on availability in the data set and a review of the pertinent natural mentoring and foster care literature (e.g., Ahrens et al., 2008; Berzin, 2008; Dubois \& Silverthorm, 2005; Munson \& McMillen, 2009). They include various individual and relationship characteristics. Individual covariates include characteristics measured at Waves 1 and 3 . Wave 3 individual characteristics are gender ( $1=$ male, $0=$ female); age (in years); race $(1=$ white, $0=$ black or other); marital status ( $1=$ married, $0=$ not married); employment status $(1=$ employed full-time, $0=$ not employed full-time); and more than one foster care placement (for former foster youth only; 1=yes, $0=$ no). Wave 1 individual characteristics are mother's use of welfare ( $1=$ yes, $0=$ no); selfreported quality of mother-child relationship ( $1=$ mother cares very much, $0=$ mother cares not so much); self-perceived relationship with peers $(1=$ friends care very much, $0=$ friends care not so much); usually feeling safe in neighborhood ( $1=y e s, 0=$ no); ever received out-ofschool suspension $(1=y e s, 0=$ no); and ever received psychological/emotional counseling (1=yes, $0=$ no).

In addition to the individual variables presented above, additional variables affecting mentoring outcomes based on previous literature were included. These are relationship duration (in years); frequency of seeing natural mentor ( $1=$ once per month or more; $0=$ less than once per month); and frequency of talking to/emailing natural mentor ( $1=$ once per month or more; $0=$ less than once per month).

\subsection{Analysis Procedures}

The general approach to assessing the impact of having a natural mentor on early adulthood outcomes involved regressing a series of outcomes on mentoring experience and 18 covariates for the former foster youth sample and 17 covariates for the other youth sample using Mplus 5.0 (Muthén \& Muthén, 2006). Multivariate path models with categorical dependent variables were estimated separately for both samples to test the hypothesis that natural mentoring relationship characteristics would be associated with decreased material hardship and asset accumulation directly and indirectly through increased income expectations, respectively. This strategy allowed for the simultaneous assessment of increased income expectations both as an outcome of natural mentoring relationship characteristics and as a predictor of emerging adulthood outcomes. Although correlation 
cannot confirm causation, intervening variables that explain the correlations between natural mentor relationship characteristics and outcomes (i.e., changes in future expectations of income) can reveal important intervention change processes. This path analytic approach yielded maximum likelihood estimates with standard errors that are robust to nonnormality and nonindependence of observations. The method uses a sandwich estimator to compute standard errors, an approach that accounts for stratification and clustering in the survey sample (Rabe-Hesketh \& Skrondal, 2006).

\section{Results}

\subsection{Natural Mentoring Among Former Foster Youth}

Residence, car, and bank account were regressed on having a natural mentor relationship while controlling for relationship characteristics at Wave 3 and individual young-adult characteristics at Waves 1 and 3. The model accounted for $47 \%$ of the variance in home ownership $\left(R^{2}=.47\right), 22 \%$ of the variance in car ownership $\left(R^{2}=.22\right)$, and $26 \%$ of the variance in having a bank account $\left(R^{2}=.26\right)$, all of which were significant. According to conventional standards, these represent large effects ( $226 \%$; Cohen, 1988). Having a natural mentor did not demonstrate a significant effect on any of the assets among young adults with previous foster care experience.

Four covariates exhibited significant effects on residence. Young adults who had previous foster care experience were more likely to own their own homes if they were married, employed full time, or had a high-quality mother-child relationship at Wave 1. Frequency of seeing one's natural mentor was associated with the lack of residence ownership.

Two covariates had significant effects on owning a car. Being employed full time was positively associated with car ownership, whereas mother's use of welfare at Wave 1 was negatively associated with the lack of car ownership.

Three covariates had significant effects on having a bank account. Being older and employed full time were associated with having a bank account, and mother's use of welfare at Wave 1 was negatively associated with having a bank account.

\subsection{Natural Mentoring Among Nonformer Foster Youth}

Residence, car, and bank account were regressed on having a natural mentor relationship while controlling for relationship characteristics at Wave 3 and individual young-adult characteristics at Waves 1 and 3 (Figure 1). The model accounted for 24\% of the variance in home ownership $\left(R^{2}=.24\right), 22 \%$ of the variance in car ownership $\left(R^{2}=.22\right)$, and $15 \%$ of the variance in having a bank account $\left(R^{2}=.15\right)$, all of which were significant. These represent medium effects (13\%-25\%; Cohen, 1988). Having a natural mentor was associated with having a bank account at Wave 3. Having a natural mentor did not demonstrate a significant effect on owning a residence or having a car.

Eight covariates had significant effects on residence ownership. Being older, White, married, having a full-time job, seeing one's natural mentor more frequently and having a high-quality mother-child relationship at Wave 1 were associated with residence ownership 
at Wave 3. Being male and having a natural mentor who filled more roles were associated with lack of residence ownership at Wave 3.

Ten covariates also had significant effects on owning a car. Being male, White, older, married, employed full time, seeing one's natural mentor more frequently, and positive peer relationships at Wave 1 were associated with car ownership at Wave 3. Mother's use of welfare and out-of- school suspension at Wave 1 were associated with a lack of car ownership at Wave 3.

Twelve covariates had significant effects on having a bank account. Being White, married, employed full time, talking to or emailing one's natural mentor more frequently, feeling safe in one's neighborhood at Wave 1, having a high-quality mother-child relationship at Wave 1 , and having positive peer relationships at Wave 1 were associated with having a bank account at Wave 3. Mother's use of welfare, out-of-school suspension, and receipt of psychological counseling at Wave 1 were associated with the lack of having a bank account at Wave 3. Natural mentor relationship strength and frequency of seeing one's natural mentor were also associated with the lack of having a bank account at Wave 3 .

\subsection{Natural Mentor Roles and Relationship Strength Among Former Foster Youth}

Number of natural mentor functional roles and natural mentor relationship strength were regressed on residence, car, and bank account ownership at Wave 3, adjusting for 15 total covariates (Figure 2). The model accounted for $65 \%$ of the variance in home ownership $\left(R^{2}\right.$ $=.65), 30 \%$ of the variance in car ownership $\left(R^{2}=.30\right)$, and $40 \%$ of the variance in having a bank account $\left(R^{2}=.40\right)$, all of which were statistically significant. These represent large effects ( $\geq 26 \%$; Cohen, 1988). The model accounted for none of the variance in income expectations $\left(R^{2}=.00\right)$. Having greater income expectations was associated with owning a residence at Wave 3. No other direct effects were significant. The indirect effects were not significant.

Three covariates had significant effects on owning a residence at Wave 3. Being married and employed full time were associated with owning a residence at Wave 3. Frequency of seeing one's natural mentor was associated with lack of owning a residence at Wave 3.

One covariate had a significant effect on owning a car at Wave 3. Having a high-quality mother-child relationship at Wave 1 was associated with the lack of car ownership at Wave 3.

Four covariates had significant effects on having a bank account at Wave 3. Being older and employed full time were associated with having a bank account at Wave 3. Out-of-school suspension and mother's use of welfare at Wave 1 were also associated with lack of having a bank account at Wave 3 .

Figure 3 shows the direct and indirect effects of residence ownership at Wave 3 regressed on individual natural mentor functional roles and natural mentor relationship strength, adjusting for 15 total covariates among young adults with previous foster care experience. The model accounted for $70 \%$ of the variance in home ownership $\left(R^{2}=.70\right)$, which was significant and 
represents a large effect ( $\geq 26 \%$; Cohen, 1988). The model also accounted for $5 \%$ of the variance in income expectations $\left(R^{2}=.05\right)$, which was not significant, and represents a small effect (2\%-12\%; Cohen). There was only one significant direct effect: Having a natural mentor who acts "like a parent" was associated with greater income expectations at Wave 3. The indirect effects were not significant.

Three covariates had significant effects on owning a residence at Wave 3. Being married and employed full time were associated with owning a residence at Wave 3. Frequency of seeing one's natural mentor was associated with lack of owning a residence at Wave 3.

Figure 4 shows the direct and indirect effects of car ownership at Wave 3 regressed on individual natural mentor functional roles and natural mentor relationship strength, adjusting for 15 total covariates. The model accounted for $31 \%$ of the variance in home ownership $\left(R^{2}\right.$ $=.31$ ), which was significant and represents a large effect ( $\geq 26 \%$; Cohen, 1988), and $5 \%$ of the variance in income expectations $\left(R^{2}=.04\right)$, which was not significant, and represents a small effect (2\%-12\%; Cohen). There was one significant direct effect: Having a natural mentor who was like a parent was associated with greater income expectations at Wave 3. The indirect effects were not significant.

One covariate had a significant effect on owning a residence at Wave 3. Having a highquality mother-child relationship at Wave 1 was associated with lack of owning a car at Wave 3.

Figure 5 shows the direct and indirect effects of having a bank account at Wave 3 regressed on individual natural mentor functional roles and natural mentor relationship strength, adjusting for 15 total covariates. The model accounted for $84 \%$ of the variance in having a bank account $\left(R^{2}=.84\right)$, which was significant and represents a large effect ( $226 \%$; Cohen, $1988)$, and $5 \%$ of the variance in income expectations $\left(R^{2}=.05\right)$, which was not significant and represents a small effect (2\%-12\%; Cohen). There were two significant direct effects. Having a natural mentor who was like a parent was associated with greater income expectations at Wave 3, and having a natural mentor who was a role model was associated with having a bank account at Wave 3 .

Three covariates had significant effects on having a bank account at Wave 3. Being older was associated with having a bank account at Wave 3. Mother's use of welfare at Wave 1 and relationship duration at Wave 3 were associated with lack of having a bank account at Wave 3.

\subsection{Natural Mentor Roles and Relationship Strength Among Nonformer Foster Youth}

Figure 6 shows the direct and indirect effects of residence, car, and bank account ownership at Wave 3 regressed on number of natural mentor functional roles and natural mentor relationship strength, adjusting for 14 total covariates among young adults without previous foster care experience. The model accounted for $23 \%$ of the variance in home ownership $\left(R^{2}\right.$ $=.23), 24 \%$ of the variance in car ownership $\left(R^{2}=.24\right)$, and $16 \%$ of the variance in having a bank account $\left(R^{2}=.16\right)$, all of which were statistically significant. These represent medium effects (13\%-25\%; Cohen, 1988). The model accounted for none of the variance in income 
expectations. Having a natural mentor who filled more functional roles was associated with a lack of residence ownership at Wave 3. Natural mentor relationship strength was associated with a lack of a bank account at Wave 3. Greater income expectations were associated with both car ownership and having a bank account at Wave 3 .

The number of statistically significant covariates varied by outcome. Six covariates had significant effects on residence ownership. Being White, older, married, and employed full time were associated with residence ownership at Wave 3. Seeing one's natural mentor more frequently was also associated with residence ownership at Wave 3. Being male was associated with a lack of residence ownership at Wave 3.

Nine covariates had significant effects on car ownership at Wave 3. Being male, White, older, married, employed full time, and seeing one's natural mentor more frequently were associated with car ownership at Wave 3. Positive peer relationships at Wave 1 were also associated with car ownership at Wave 3. Mother's use of welfare at Wave 1 and relationship duration were associated with lack of car ownership at Wave 3.

Eight covariates had significant effects on having a bank account at Wave 3. Being White and employed full time were associated with having a bank account at Wave 3. Positive peer relationships at Wave 1and feeling safe in one's neighborhood at Wave 1 were also associated with having a bank account at Wave 3. Frequency of seeing one's natural mentor was associated with lack of having a bank account at Wave 3. Out-of-school suspension, receipt of psychological counseling, and mother's use of welfare at Wave 1 were also associated with a lack of a bank account at Wave 3 .

Figure 7 shows the direct and indirect effects of residence ownership at Wave 3 regressed on individual natural mentor functional roles and natural mentor relationship strength, adjusting for 14 total covariates among young adults without previous foster care experience. The model accounted for $24 \%$ of the variance in home ownership $\left(R^{2}=.24\right)$ and $2 \%$ of the variance in income expectations $\left(R^{2}=.02\right)$, both of which were statistically significant. This represents a medium effect (13\%-25\%; Cohen, 1988) for the former and a small effect (2\%$12 \%$; Cohen) for the latter. A natural mentor who provided guidance or advice, emotional nurturance, or was considered a role model was associated with lack of residence ownership at Wave 3.

There were six significant covariates. Being White, older, married, and employed full time were associated with owning a residence at Wave 3. Seeing one's mentor more frequently was also associated with owning a residence at Wave 3. Being male was associated with the lack of residence ownership at Wave 3 .

Figure 8 shows the direct and indirect effects of car ownership at Wave 3 regressed on individual natural mentor functional roles and natural mentor relationship strength, adjusting for 14 total covariates among young adults without previous foster care experience. The model accounted for $24 \%$ of the variance in car ownership $\left(R^{2}=.24\right)$ and $2 \%$ of the variance in income expectations $\left(R^{2}=.02\right)$, both of which were statistically significant. This represents a medium effect (13\%-25\%; Cohen, 1988) for the former and a small effect (2\%$12 \%$; Cohen) for the latter. Having a natural mentor who was like a parent was associated 
with car ownership at Wave 3. Having greater income expectations was also associated with car ownership at Wave 3. Having a natural mentor who provided guidance or advice was associated with greater income expectations at Wave 3.

There were nine significant covariates. Being male, White, older, married, having a full time job, seeing one's mentor more frequently, and having positive peer relationships at Wave 1 were associated with car ownership at Wave 3. Mother's use of welfare at Wave 1and natural mentor relationship length were associated with lack of car ownership at Wave 3.

Figure 9 shows the direct and indirect effects of having a bank account at Wave 3 regressed on individual natural mentor functional roles and natural mentor relationship strength, adjusting for 14 total covariates among young adults without previous foster care experience. The model accounted for $17 \%$ of the variance in having a bank account $\left(R^{2}=\right.$. $17)$ and $2 \%$ of the variance in income expectations $\left(R^{2}=.02\right)$, both of which were statistically significant and represent medium (13\%-25\%; Cohen, 1988) and small effects (2\%-12\%; Cohen), respectively. Natural mentors who provided guidance or advice or who were considered role models were associated with having a bank account at Wave 3. Giving guidance or advice was also associated with greater income expectations at Wave 3. Greater income expectations were associated with having a bank account at Wave 3. Natural mentor relationship strength and practical help were associated with the lack of having a bank account at Wave 3.

There were eight significant covariates. Being White, employed full time, feeling safe in one's neighborhood at Wave 1, and having positive peer relationships at Wave 1 were associated with having a bank account at Wave 3. Mother's use of welfare, out-of-school suspension, and receipt of psychological counseling at Wave 1 were associated with not having a bank account at Wave 3. Frequency of seeing one's natural mentor was also associated with a lack of a bank account at Wave 3.

\section{Discussion}

The two samples shared one pattern of association among the direct effects in the assets analysis; that is, having a natural mentor who served as a role model was associated with having a bank account. Among the nonformer foster youth sample only, having a mentor who was a role model was also associated with increased income expectations. The importance of role modeling for succeeding in the developmental tasks associated with emerging adulthood is consistent with both theory and previous research. Social learning theory (Bandura, 1977) posits that people learn from one another, via observation, imitation, and modeling, and that learning by doing is most successful when guided by somebody who already knows (Hamilton \& Hamilton, 2005).

This analysis suggests that natural mentors have the potential to be the "somebody who already knows" when it comes to having a bank account in young adulthood. The rolemodel finding also aligns with previous research that has established its centrality to all types of mentoring (Liang, Spencer, Brogan, \& Corral, 2008; Rhodes, Spencer, Keller, Liang, \& Noam, 2006). Although the results of this analysis did not confirm the mediation hypothesis for "role model," it remains plausible that the pathway by which this natural 
mentor functional role achieves positive outcomes is through the development of optimistic future expectations (i.e., greater income expectations) (Rhodes et al., 2006).

Youth in the general population primarily observe, imitate, and model their parents when it comes to succeeding with developmental tasks, including achieving financial literacy. This analysis suggests that a natural mentor may also serve this critical purpose by role modeling. This implication is particularly salient for the former foster youth sample, given the decreased likelihood of them having appropriate adults available for such purposes.

Natural mentoring was not associated with owning one's own residence for either the nonformer foster youth or the former foster youth. A possible substantive explanation for this finding relates to the age range of sample respondents. The young adults in both groups were between the ages of 18 and 26, and only $12 \%$ and $11 \%$ of the former foster youth and nonformer foster youth owned their own residences, respectively. Similar to the delinquency and violence outcome, these results indicate a floor effect. The small number of respondents reporting residence ownership was in turn associated with difficulty in finding other variables associated with it. The percentage of respondents reporting owning their residence is also consistent with national homeownership data. According to the most recent (2005) America Housing Survey, the average age of first time homebuyers is 33 (Eisenberg, 2008). Therefore, the outcome of owning one's residence may be an unrealistic expectation for the Add Health young adults at Wave 3. It is plausible that replication of this particular analysis using homeownership at Wave 4 might yield a different result.

Turning to results unique to the nonformer foster youth sample, a natural mentor relationship was associated with having a bank account at Wave 3. In addition to the rolemodel finding discussed previously, the natural mentor role of providing guidance or advice was also associated with having a bank account. The importance of natural mentors' role modeling and providing guidance advice vis-à-vis the outcome of having a bank account is consistent with asset-building theory. Access to information and education about assets and asset building is considered integral to the adoption of savings behavior (Sherraden, 2008). The results of this analysis suggest that natural mentors who are role models and who provide guidance or advice can facilitate financial literacy.

In addition to being a role model and providing guidance or advice, having a natural mentor who was like a parent was associated with car ownership for the nonformer foster youth group. This may have been a function of the inability to account for the possibility of parental support simultaneously. Although the quality of the mother-child relationship at Wave 1 was adjusted for in all models, how that relationship fared through emerging adulthood (or how parent-adolescent relations fare more generally) is unknown. Car ownership at Wave 3 may then reflect the normative developmental process that most middle- to upper-class teenagers in the general population experience when they have access to parental support and resources.

\section{Strengths \& Limitations}

The strengths and limitations of this research deserve comment. Research on naturally occurring mentoring relationships is in a nascent stage of development, and therefore 
empirical information is still rather limited. This is particularly true for special populations, such as former foster youth. For this reason, the most significant contribution of this study is a better understanding of the relationship characteristics and processes that may influence emerging adulthood outcomes among both special and normative populations. Furthermore, this paper is the first to consider the association between natural mentoring and assetsrelated outcomes.

To date, most of the mentoring research has focused on whether the presence of such relationships is associated with improved outcomes among youth. We know little about specific relationship characteristics, including the quality of the relationship with and the roles filled by natural mentors, as well as their associations with emerging adulthood outcomes. Moreover, this is the first exploratory study to compare two distinct populations with plausibly unique relationship characteristics and needs in one set of analyses. Although we cannot say whether the differences observed between the former foster youth group and nonformer foster youth group were "statistically significant," the results provide important initial insight into potential areas for future investigation.

Another important strength of this study is the sophisticated, multivariate data analytic procedures employed. The analytic framework allowed for model testing and examination of phenomena that occur at the dyadic level in relationships (DuBois et al., 2006). Although the specific meditational pathway was not supported, this work is a valuable example of the type of mechanistic research that is needed to further advance the field of youth mentoring. The relationship between a caring adult and a young person is at the heart of natural mentoring. Therefore, understanding how these relationships work and for whom is critical (DuBois \& Rhodes, 2006).

It is important to note that even though the results were discussed as an indication of the role of natural mentors for outcomes as protective and promotive, these distinctions are based on the conceptual and theoretical approaches typical of mentoring studies. The analyses cannot indicate cause and effect relationships because the temporal precedence of the predictors is uncertain. Second, because these analyses were based on a secondary dataset, the measurement of the future-expectations construct, although acceptable, was not ideal.

An additional limitation of this study concerns sample definition for the former foster youth group. Add Health, the largest and most comprehensive survey of adolescents ever undertaken, was not designed with child welfare studies in mind a priori. Therefore, the former foster youth sample is less well defined in the data set as compared to samples in child welfare-focused surveys (e.g., National Survey of Child and Adolescent Wellbeing). Specifically, the former foster youth included in this analysis were defined by one survey question, which asked whether the respondent had ever lived in a foster home. Compared to other child welfare samples, this is a less precise operationalization of the foster care experience. The implication for sample definition involves the possibility of introducing bias with respect to the results for the former foster youth group in Add Health. Yet, compared to other large child welfare surveys, Add Health is unique in that it includes specific questions related to processes and characteristics of natural mentoring relationships. The dataset also includes an adequate subset of youth who report having experienced foster care. Therefore, 
this data resource is unique, making it possible to compare a sample of naturally mentored young adults who identify themselves as former foster youth to a sample of naturally mentored young adults from the normative population.

Another limitation concerns the assets-related measures. Homeownership may not be relevant to the Add Health respondents at Wave 3 because at this wave, respondents are generally too young to own their own homes. There may also be other assets-related indicators that would be more relevant to this age group, yet are unavailable in the Add Health dataset. For example, the main asset building outcome, net worth, was not included. Therefore, an additional limitation in this study involves data constraints with respect to assets-related variables available for analysis.

Statistical power is also a concern. Power refers to the probability of rejecting the null hypothesis when there is a real effect in the population (Kline, 2005) and varies directly with the magnitude of the real population effect, the sample size, and the $p$ value selected for statistical tests. The implications of this are twofold: (a) effects that are actually present in the former foster youth sample may be undetectable due to the small sample size, and (b) effects that are present in the very large nonformer foster youth sample may be detectable, but are apt to be so small that they are clinically irrelevant. Despite the issues of power inherent in using Add Health to analyze former foster youths' outcomes, this exploratory research provides valuable initial clues regarding directions for future research and intervention development.

\section{Implications}

This study makes an important contribution to the natural mentoring evidence base by highlighting the importance of considering relationship characteristics and processes. Moreover, focusing on assets-related outcomes is a novel approach to investigating the benefits of natural mentoring to the healthy development of youth, and this paper is the first to consider such an association. Results tie certain natural mentoring characteristics to assets-related outcomes, controlling for a variety of individual and relationship characteristics. This association is a first step in justifying the practice of incorporating natural mentoring relationships into standard permanency planning practices in child welfare in an effort to mitigate the risk associated with aging out of foster care. This association is also the first step in justifying natural mentoring as an assets-building intervention for both normative and child welfare populations.

In conclusion, this study contributes to the growing body of literature on natural mentoring and former foster youth. It also adds to the emerging literature on developing ways to intervene to help older foster youth emancipate from foster care and transition to adulthood more successfully. Future research with longitudinal data to confirm casual relationships is needed. Future research that builds on the results of this study by considering natural mentor relationship characteristics and processes is also required. A commitment to achieving this deeper understanding of these relationships will shed light on how having "one adult who is crazy about you" can alter youth's life trajectories by opening new opportunities and creating lasting change. 


\section{Acknowledgments}

This research uses data from Add Health, a program project designed by J. Richard Udry, Peter S. Bearman, and Kathleen Mullan Harris, and funded by a grant P01-HD31921 from the Eunice Kennedy Shriver National Institute of Child Health and Human Development, with cooperative funding from 17 other agencies. Special acknowledgment is due Ronald R. Rindfuss and Barbara Entwisle for assistance in the original design. Persons interested in obtaining data files from Add Health should contact Add Health, Carolina Population Center, 123 W. Franklin Street, Chapel Hill, NC 27516-2524 (addhealth@unc.edu). No direct support was received from grant P01-HD31921 for this analysis.

\section{References}

Ahrens KR, DuBois DL, Richardson LP, Fan M, Lozano P. Youth in foster care with adult mentors during adolescence have improved adult outcomes. Pediatrics. 2008; 121(2):e1-e7. [PubMed: 18070931]

Aronowitz T, Morrison-Beedy D. Resilience to risk-taking behaviors in impoverished African American girls: The role of mother-daughter connectedness. Research in Nursing \& Health. 2004; 27:29-39. [PubMed: 14745854]

Bandura, A. Social learning theory. New York: General Learning Press; 1977.

Beam MR, Chen C, Greenberger E. The nature of adolescents' relationships with their "very important" nonparental adults. American Journal of Community Psychology. 2002; 30(2):305-325. [PubMed: 12002248]

Berzin SC. Difficulties in the transition to adulthood: Using propensity scoring to understand what makes foster youth vulnerable. Social Service Review. 2008 Jun.:171-196.

Britner PA, Balcazar FE, Blechman EA, Blinn-Pike L, Larose S. Mentoring special youth populations. Journal of Community Psychology. 2006; 34(6):747-763.

Byrne, BM. Structural equation modeling with AMOS: Basic concepts, applications, and programming. Philadelphia, PA: Lawrence Erlbaum; 2001.

Cabrera, P.; Auslander, W. Future orientation and relationship to mental health, trauma histories, and risk behaviors in foster care adolescents. Paper session presented at the 11th Annual Meeting of the Society for Social Work and Research; San Francisco, CA. 2007.

Cohen, J. Statistical power analysis for the behavioral sciences. 2. Hillsdale, NJ: Lawrence Earlbaum Associates; 1988.

Corporation for Enterprise Development. American Dream Demonstration Overview. (n.d.)Retrieved May 18, 2009, from http://add.cfed.org/overview.html

Courtney, ME.; Dworsky, A.; Cusick, GR.; Havlicek, J.; Perez, A.; Keller, T. Midwest evaluation of the adult functioning of former foster youth: Outcomes at age 21. Chicago, IL: Chapin Hall Center for Children at the University of Chicago; 2007.

Courtney, ME.; Lyons, S. Mentoring relationships and adult outcomes for foster youth in transition to adulthood. Paper Session Presented at the 13th Annual Meeting of the Society for Social Work and Research; New Orleans, LA. 2009.

Dietz RD, Haurin DR. The social and private micro-level consequences of homeownership. Journal of Urban Economics. 2003; 54:401-450.

DuBois DL, Silverthorn N. Natural mentoring relationships and adolescent health: Evidence from a national study. American Journal of Public Health. 2005; 95:518-524. [PubMed: 15727987]

Galster, GC. Home ownership and neighborhood reinvestment. Durham, NC: Duke University Press; 1987.

Garmezy, N. Stress-resistant children: The search for protective factors. In: Stevenson, JE., editor. Recent research in developmental psychopathology. Oxford: Pergamon; 1985.

Green RK, White MJ. Measuring the benefits of home owning: Effects on children. Journal of Urban Economics. 1997; 41:441-461.

Greeson JKP, Bowen NK. "She holds my hand" The experiences of foster youth with their natural mentors. Children and Youth Services Review. 2008; 30(10):1178-1188. 
Hamilton, MA.; Hamilton, SF. Work and service-learning. In: DuBois, DL.; Karcher, MJ., editors. Handbook of youth mentoring. Thousand Oaks, CA: SAGE Publications; 2005. p. 348-363.

Hamilton SF, Hamilton MA, Hirsch BJ, Hughes J, King J, Maron K. Community contexts for mentoring. Journal of Community Psychology. 2006; 34(6):727-746.

Harris, KM.; Florey, F.; Tabor, J.; Bearman, PS.; Jones, J.; Udry, JR. The National Longitudinal Study of Adolescent Health: Research design. 2003. Retrieved April 2, 2008, from http:// www.cpc.unc.edu.libproxy.lib.unc.edu/projects/addhealth/design

Henretta JC. Parental status and child's home ownership. American Sociological Review. 1984; 49:131-140.

$\mathrm{Hu}$ L, Bentler PM. Cutoff criteria for fit indexes in covariance structure analysis: Conventional criteria versus new alternatives. Structural Equation Modeling. 1999; 6:1-55.

Kenny, DA. Mediation. 2008. Retrieved February 15, 2009, from http://davidakenny.net/cm/ mediate.htm

Kline, RB. Principles and practice of structural equation modeling. 2. New York: Guilford Press; 2005.

McDonald S, Erickson LD, Johnson MK, Elder GH. Informal mentoring and young adult employment. Social Science Research. 2007; 36:1328-1347. [PubMed: 19050736]

Munson MR, McMillen JC. Natural mentoring and psychosocial outcomes among older youth transitioning from foster care. Children and Youth Services Review. 2009; 31(1):104-111. [PubMed: 20046218]

Muthén, LK.; Muthén, BO. Mplus user's guide. 5. Los Angeles, CA: Muthén \& Muthén; 1998-2007.

Noponen H. Loans to the working poor: A longitudinal study of credit, gender and the household economy. International Journal of Urban and Regional Research. 1992; 16:234-251.

Olds D, Kitzman H, Cole R, Robinson J. Theoretical foundations of a program of home visitation for pregnant women and parents of young children. Journal of Community Psychology. 1997; 25:925.

Oskamp S, Harrington MJ, Edwards TC, Sherwood DI, Okuda SM, Swanson DC. Factors influencing household recycling behavior. Environment and Behavior. 1991; 23:494-519.

Page-Adams, D.; Scanlon, E.; Beverly, S.; McDonald, T. Assets, health, and well-being: Neighborhoods, families, children and youth (CSD report). St. Louis, MO: Washington University, Center for Social Development; 2001.

Page-Adams D, Sherraden M. Asset building as a community revitalization strategy. Social Work. 1997; 42(5):423-434.

Pecora PJ, Kessler RC, O’Brien KO, White CR, Williams J, Hiripi E, et al. Educational and employment outcomes of adults formerly placed in foster care: Results from the northwest foster care alumni study. Children and Youth Services Review. 2006; 28:1459-1481.

Pecora, PJ.; Kessler, RC.; Williams, J.; O’Brien, K.; Downs, AC.; English, D., et al. Improving family foster care: Findings from the Northwest Foster Care Alumni Study. Seattle, WA: Casey Family Programs; 2005.

Perkins DD, Florin P, Rich RC, Wandersman A, Chavis DM. Participation and the social and physical environment of residential blocks: Crime and community context. American Journal of Community Psychology. 1990; 18:83-115.

Rabe-Hesketh S, Skrondal A. Multilevel modeling of complex survey data. Journal of the Royal Statistical Society: Series A (Statistics in Society). 2006; 169(4):805-827.

Rhodes, JE.; Boburg, S. Becoming Manny: Inside the life of baseball's most enigmatic slugger. New York: Scribner; 2009.

Rhodes JE, DuBois DL. Understanding and facilitating the youth mentoring movement. Social Policy Report. 2006; 20(3):3-19.

Rhodes JE, Spencer R, Keller TE, Liang B, Noam G. A model for the influence of mentoring relationships on youth development. Journal of Community Psychology. 2006; 34(6):691-707.

Robbins RN, Bryan A. Relationship between future orientation, impulsive sensation seeking, and risk behavior among adjudicated adolescents. Journal of Adolescent Research. 2004; 19(4):428-445.

[PubMed: 16429605] 
Robert S, House JS. SES differentials in health by age and alternative indicators of SES. Journal of Aging and Health. 1996; 8:359-388. [PubMed: 10165980]

Rohe WM, Stegman MA. The effects of home ownership on the self-esteem, perceived control and life satisfaction of low-income people. The Journal of the American Planning Association. 1994a; 60:173-184.

Rohe WM, Stegman MA. The impact of home ownership on the social and political involvement of low-income people. Urban Affairs Quarterly. 1994b; 30:152-172.

Rosen, B. SEED accounts and foster youth. 2007. Retrieved April 1, 2009, from http://www.cfed.org/ imageManager/_documents/Growing_Knowledge_Dec07.pdf

Rutter M. Psychosocial resilience and protective mechanisms. American Journal of Orthopsychiatry. 1987; 57:316-331. [PubMed: 3303954]

Sherraden, M. Asset building: Theoretical background and research questions. St. Louis, MO: Washington University, Center for Social Development; 2008.

Somers CL, Gizzi TJ. Predicting adolescents' risky behaviors: The influence of future orientation, school involvement, and school attachment. Adolescent \& Family Health. 2001; 2(1):3-11.

U.S. Census Bureau. Homeownership rates by area. 2008. Retrieved April 1, 2009, from http:// www.census.gov/hhes/www/housing/hvs/annual08/ann08t14.xls

U.S. Census Bureau. Homeownership rates by age of householder. 2009. Retrieved May 18, 2009, from http://www.census.gov/hhes/www/housing/hvs/qtr109/q109ind.html

Van Zandt S, Rohe WM. Do first-time home buyers improve their neighborhood quality? Journal of Urban Affairs. 2006; 28(5):491-510.

Werner, EE.; Smith, RS. Journeys from childhood to midlife: Risk, resilience, and recovery. Ithaca, NY: Cornell University Press; 2001.

Whitbeck LB, Simons RL, Conger RD, Lorenz FO, Huck S, Elder GH Jr. Family economic hardship, parental support, and adolescent self-esteem. Social Psychology Quarterly. 1991; 54:353-363.

Yadama GN, Sherraden M. Effects of assets on attitudes and behaviors: Advance test of a social policy proposal. Social Work Research. 1996; 20:3-11. 


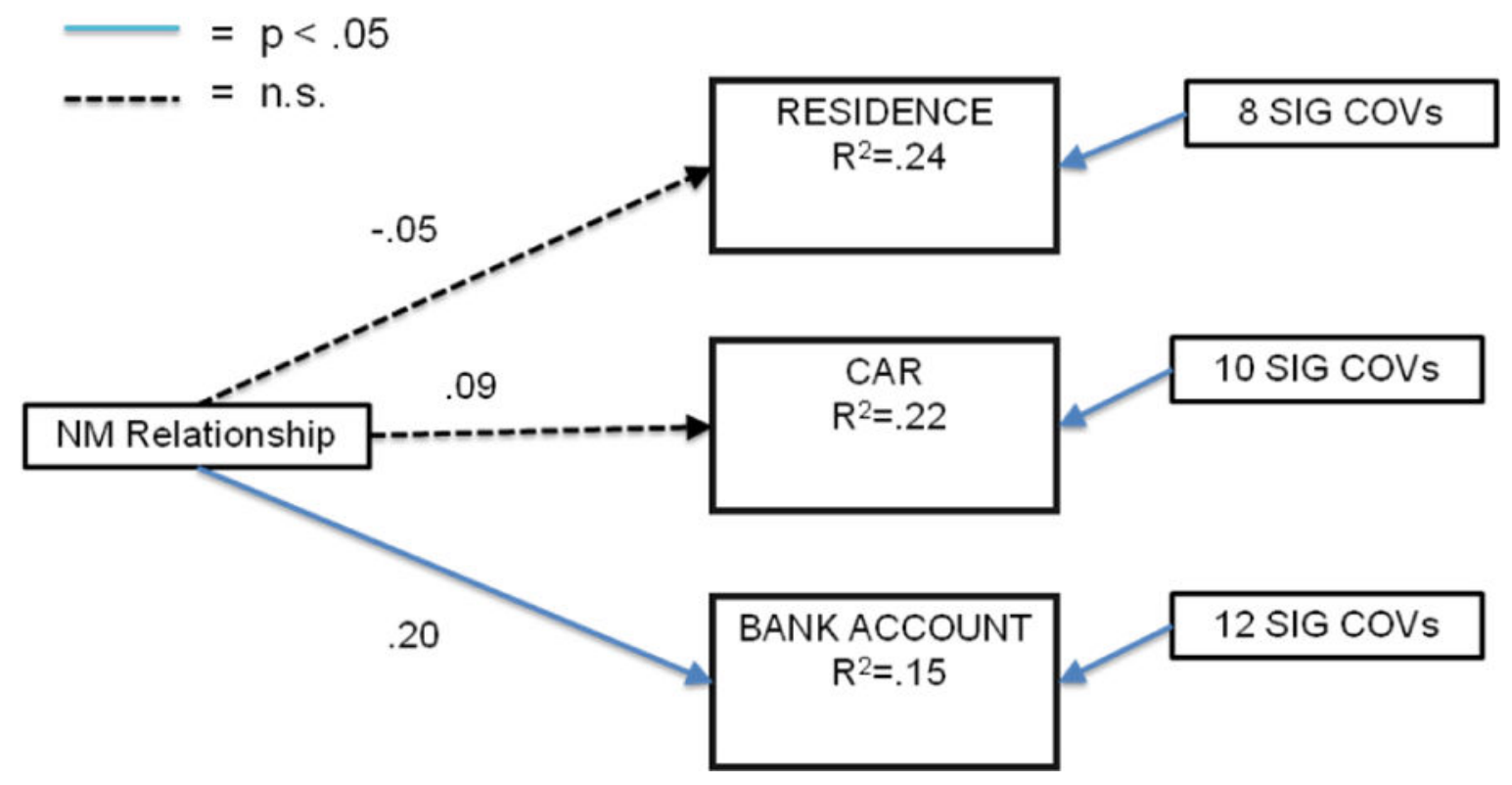

Figure 1.

Direct effect of having a natural mentor relationship on assets at Wave 3 among young adults without previous foster care experiences, adjusting for 17 total covariates $(n=9,373)$. 

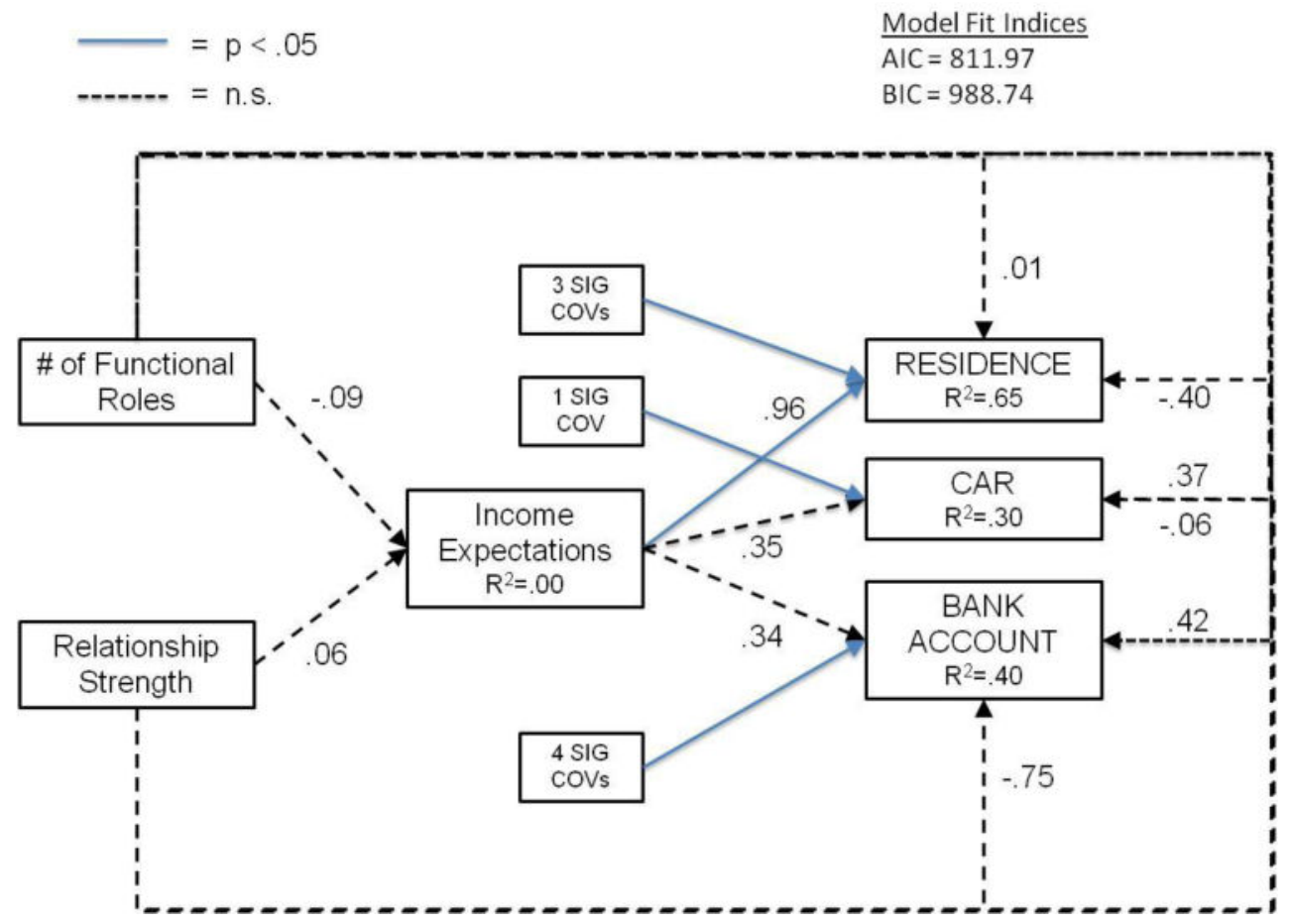

Figure 2.

Direct and indirect effects of number of natural mentor functional roles and strength of natural mentor relationship on assets at Wave 3, adjusting for 17 total covariates among young adults with previous foster care experience $(n=134)$. 

$=p<.05$
Model Fit Indices
- n.s.-...
$\mathrm{AIC}=478.72$
$\mathrm{BIC}=568.55$

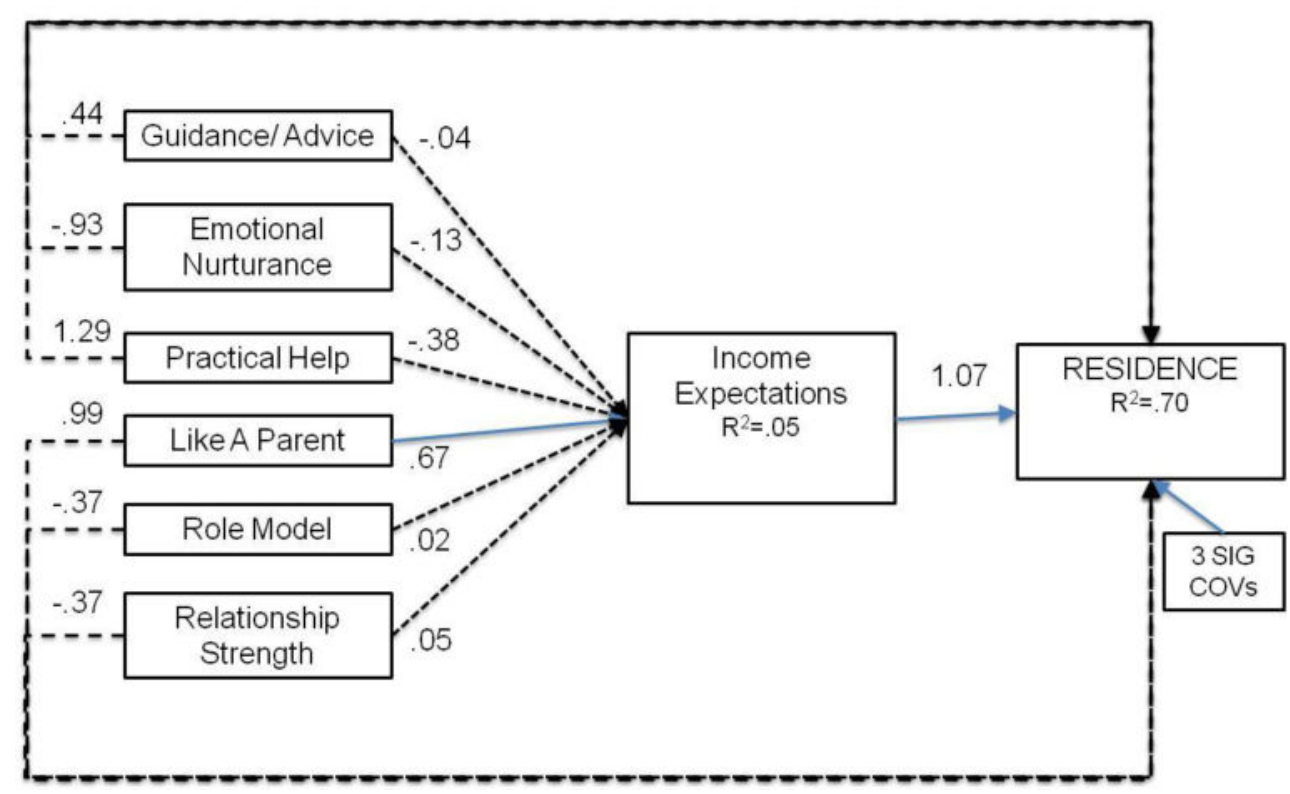

Figure 3.

Direct and indirect effects of individual natural mentor functional roles and strength of natural mentor relationship on residence ownership at Wave 3, adjusting for 17 total covariates among young adults with previous foster care experience $(n=134)$. 


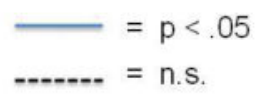

Model Fit Indices

- n.s.-...

$\mathrm{AIC}=558.30$

$\mathrm{BIC}=648.13$

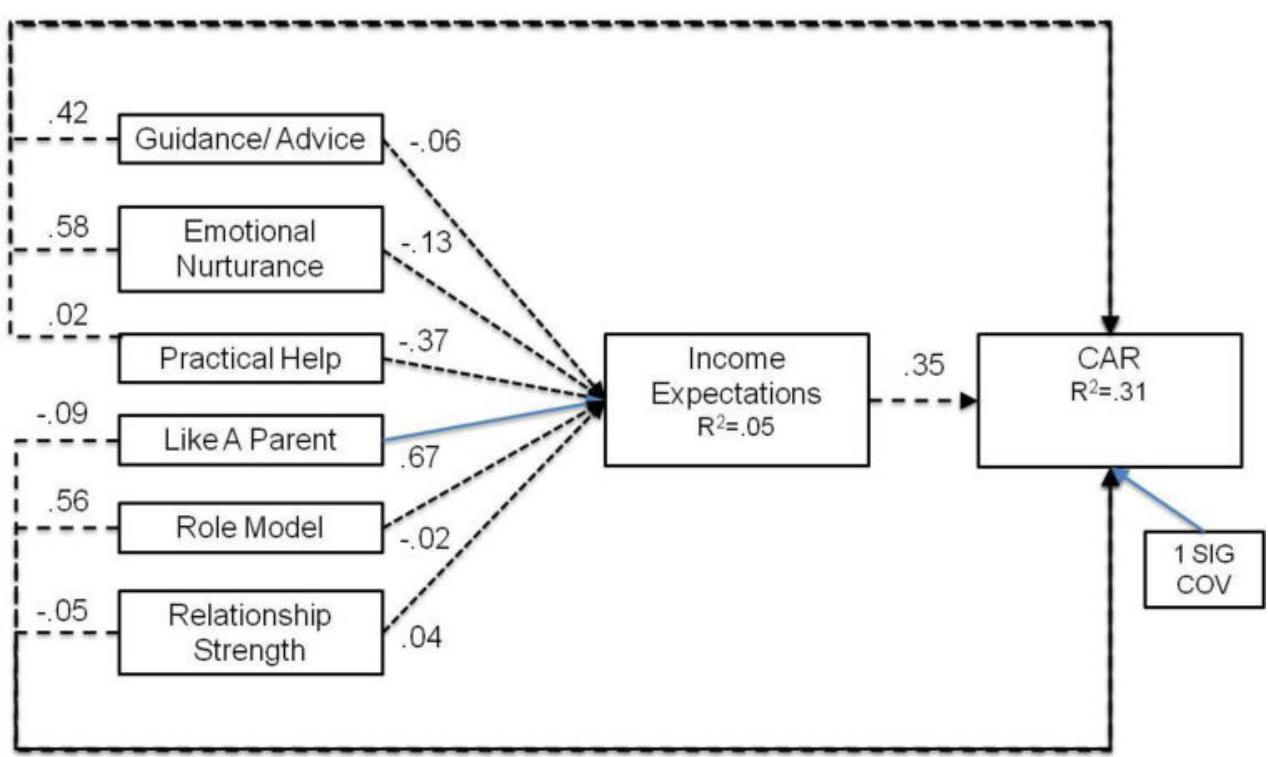

Figure 4.

Direct and indirect effects of individual natural mentor functional roles and strength of natural mentor relationship on car ownership at Wave 3, adjusting for 17 total covariates among young adults with previous foster care experience $(\mathrm{n}=134)$. 


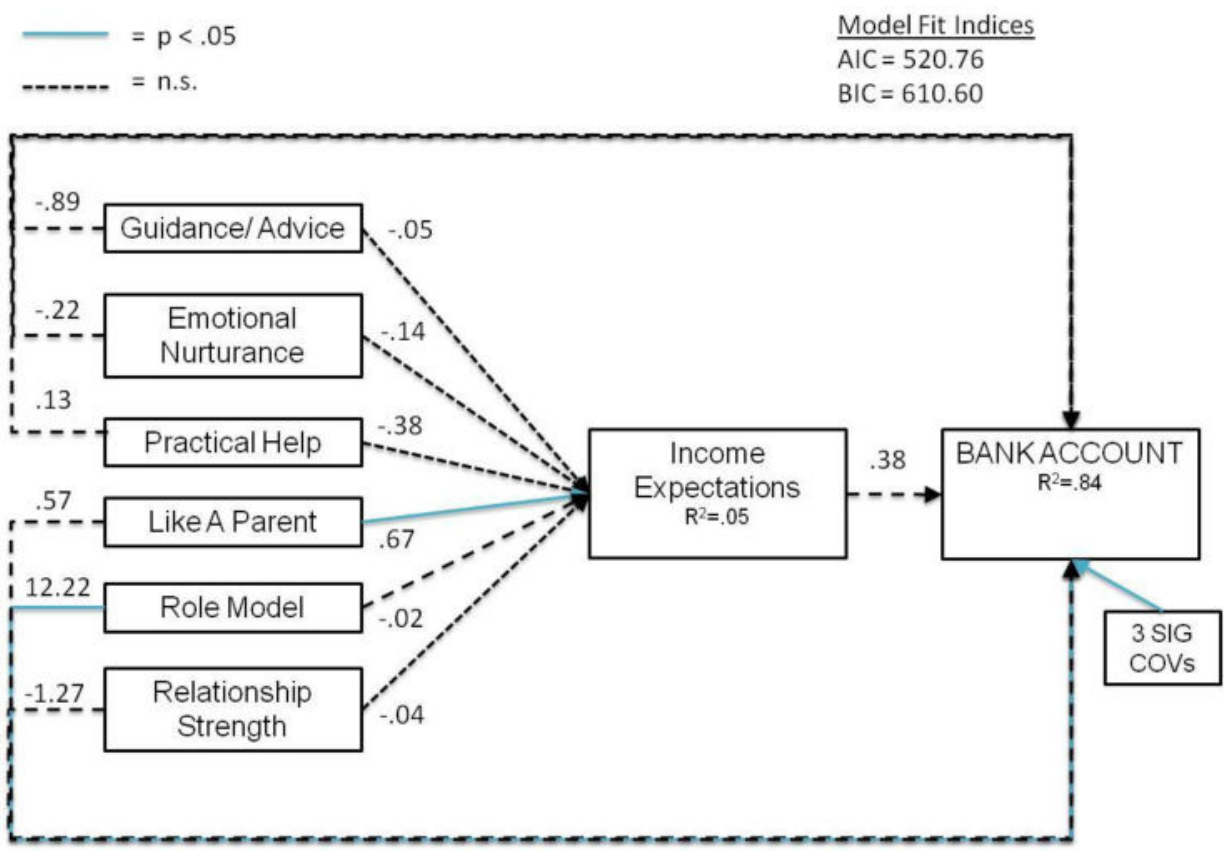

Figure 5.

Direct and indirect effects of individual natural mentor functional roles and strength of natural mentor relationship on bank account ownership at Wave 3, adjusting for 17 total covariates among young adults with previous foster care experience $(n=134)$. 


$$
\begin{aligned}
& =p<.05 \\
\ldots-.- & =\text { n.s. }
\end{aligned}
$$

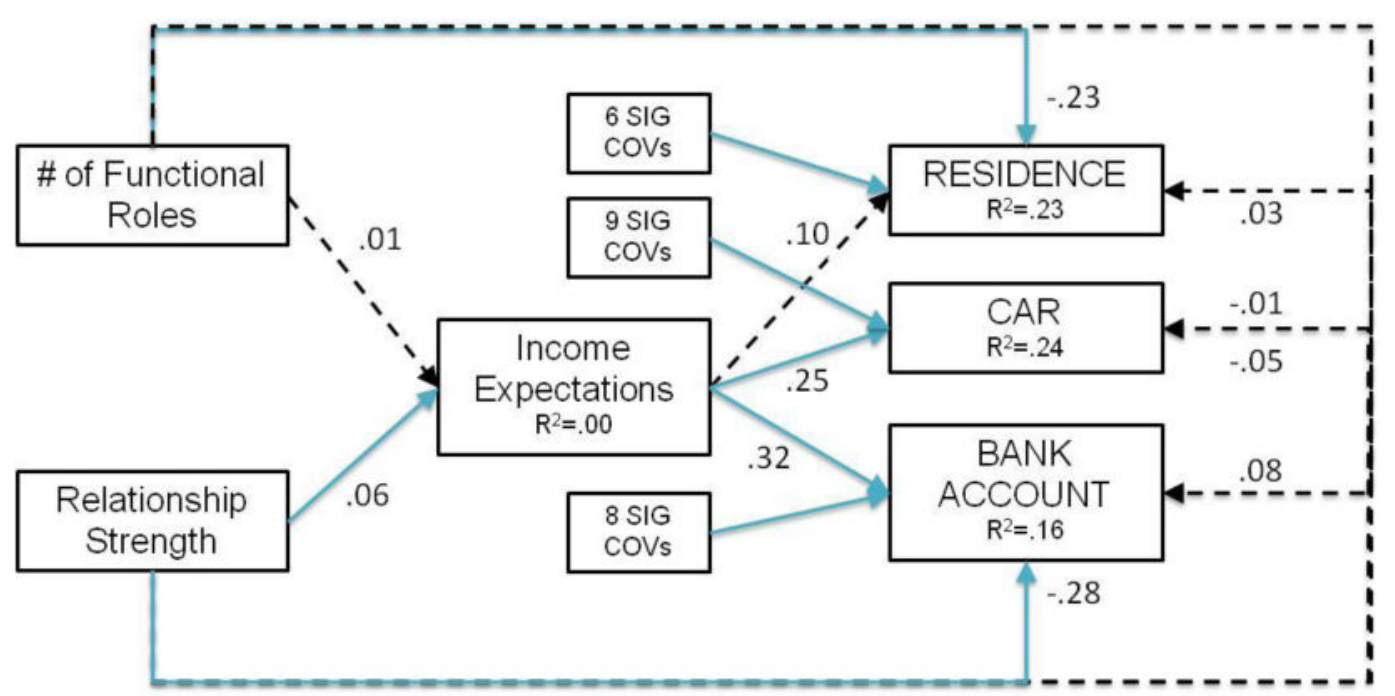

Figure 6.

Direct and indirect effects of number of natural mentor functional roles and strength of natural mentor relationship on assets at Wave 3, adjusting for 16 total covariates among young adults without previous foster care experience $(n=6,889)$.
Model Fit Indices

$\mathrm{AIC}=32005.76$

$\mathrm{BIC}=32402.34$ 


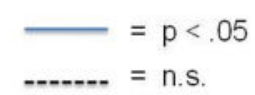

Model Fit Indices

$\mathrm{AIC}=20097.84$

$=\mathrm{n} . \mathrm{s}$.

$\mathrm{BIC}=20309.80$

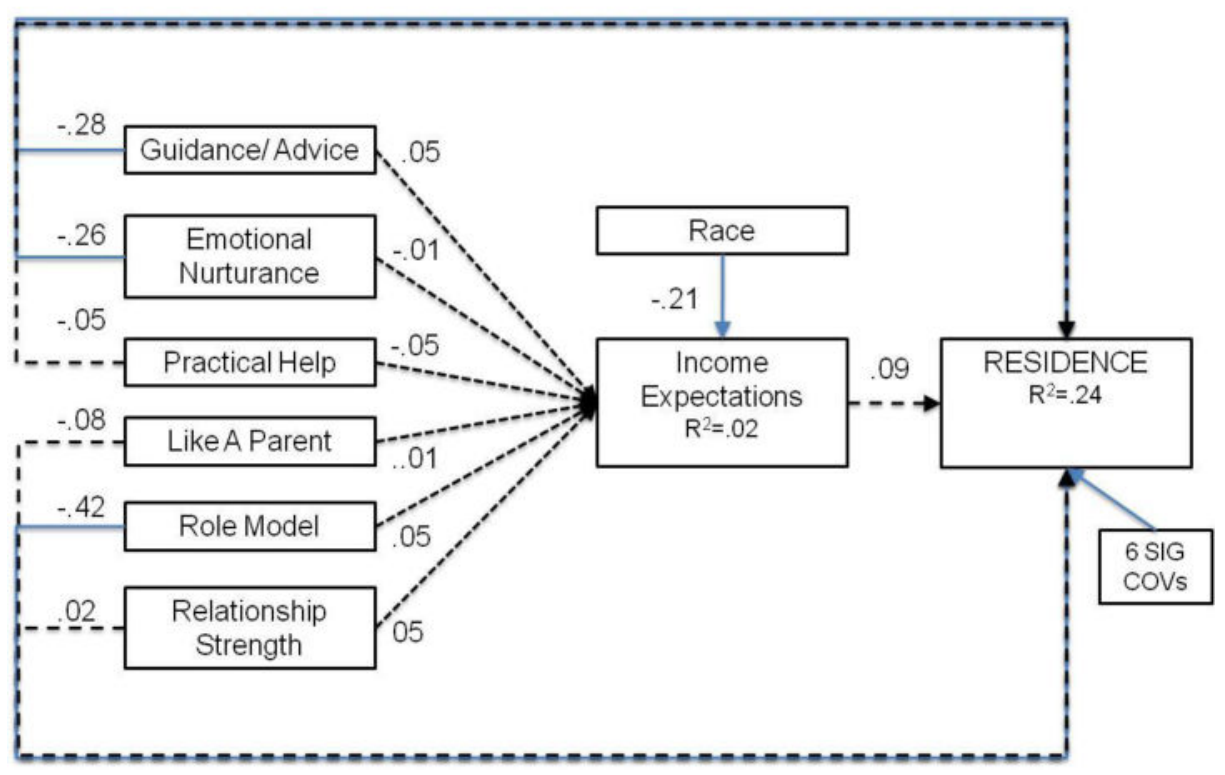

Figure 7.

Direct and indirect effects of individual natural mentor functional roles and strength of natural mentor relationship on residence ownership at Wave 3, adjusting for 16 total covariates among young adults without previous foster care experience $(n=6,887)$. 


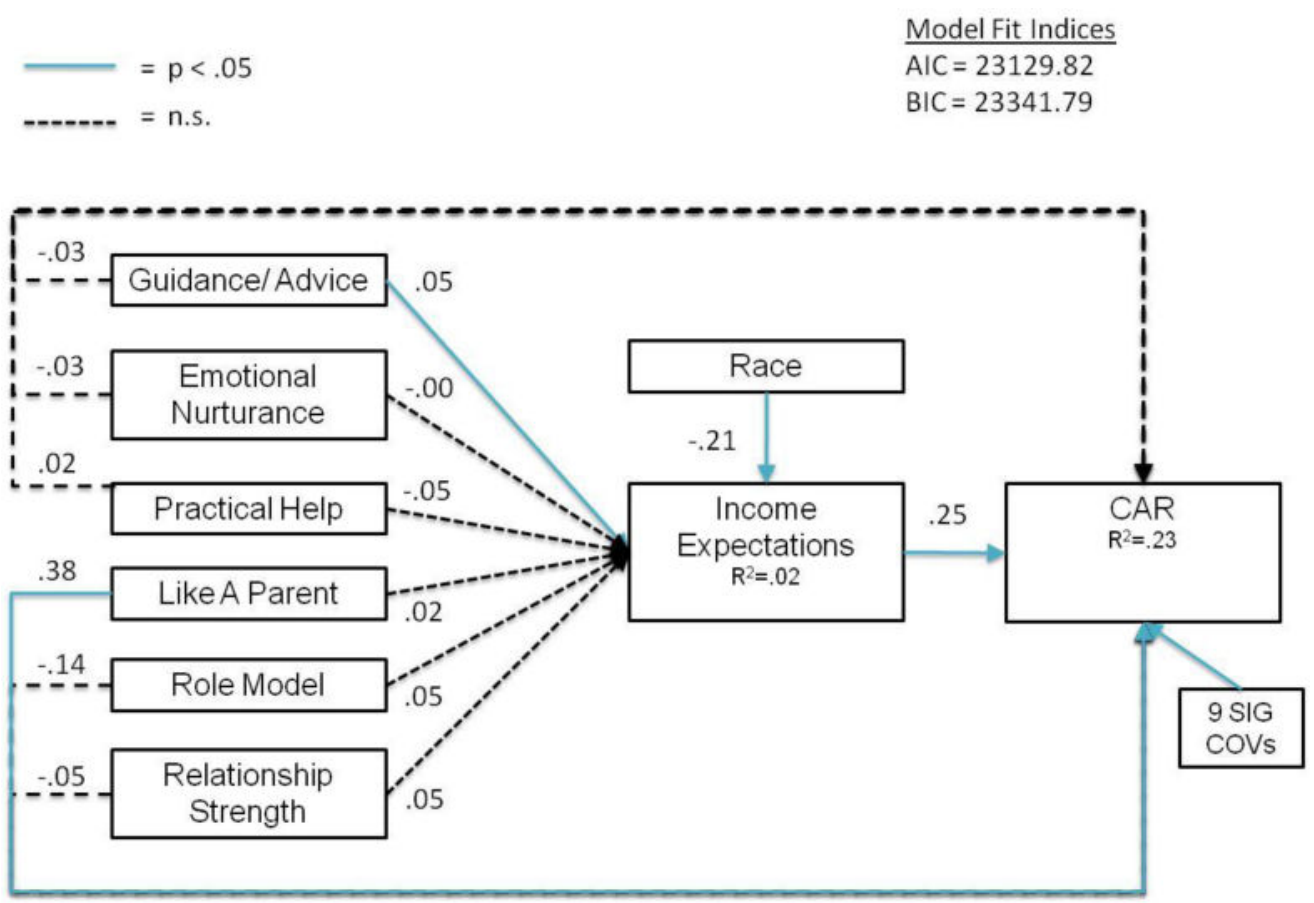

Figure 8.

Direct and indirect effects of individual natural mentor functional roles and strength of natural mentor relationship on car ownership at Wave 3, adjusting for 16 total covariates among young adults without previous foster care experience $(n=6,889)$. 


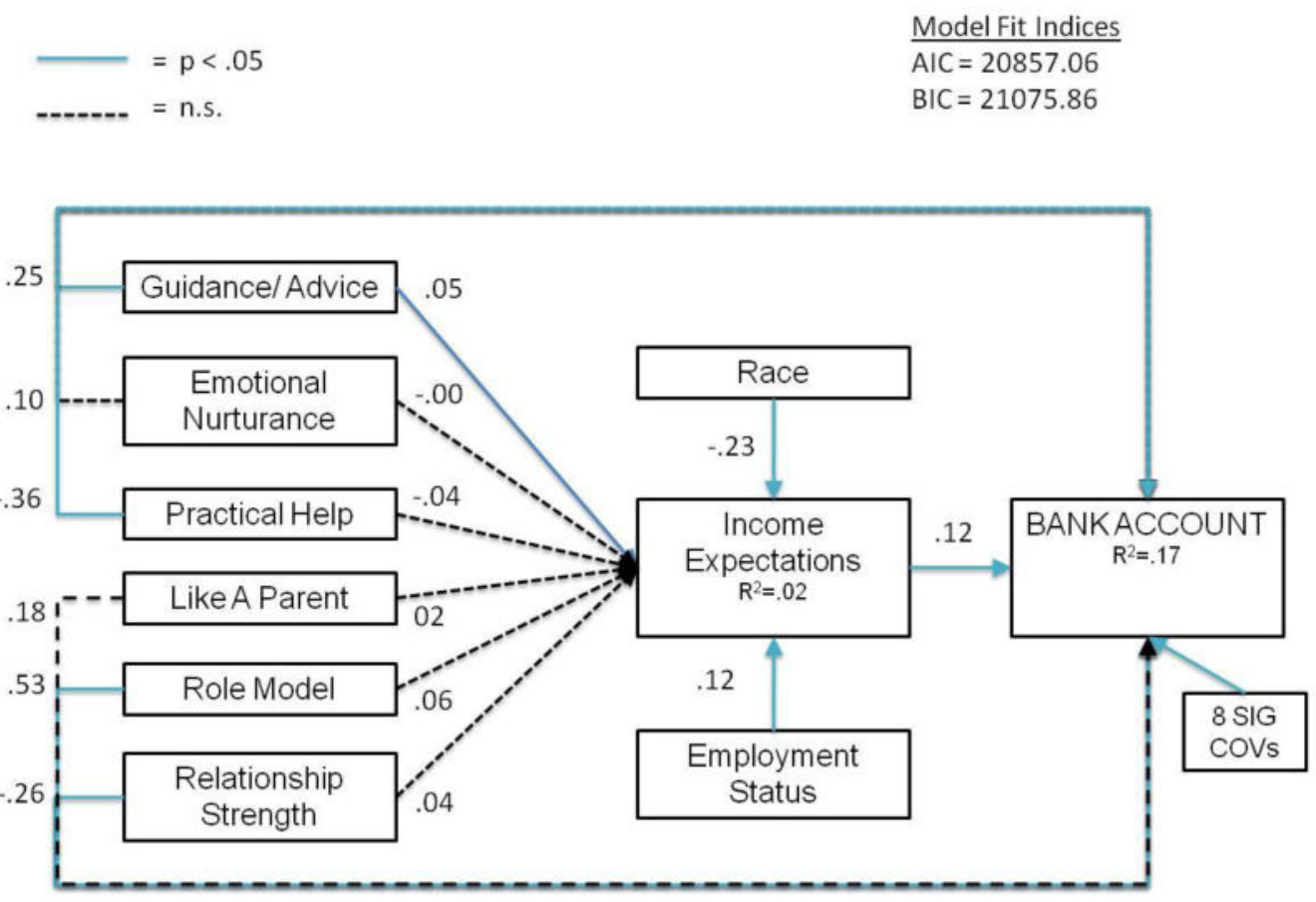

Figure 9.

Direct and indirect effects of individual natural mentor functional roles and strength of natural mentor relationship on bank account ownership at Wave 3, adjusting for 16 total covariates among young adults without previous foster care experience $(n=6,889)$. 
Table 1

Descriptive Statistics for Former Foster Youth and Nonformer Foster Youth With Natural Mentors (NM)

\begin{tabular}{|c|c|c|c|}
\hline Variable & Former foster youth $\% / M(S D)$ & Nonformer foster youth \%/M (SD) & $\chi^{2} / t$ \\
\hline \multicolumn{4}{|l|}{$\underline{\text { Young-adult characteristics (Wave 3) }}$} \\
\hline Female & .66 & .51 & 3.37 \\
\hline White & .74 & .80 & 1.27 \\
\hline Non-Hispanic & .97 & .90 & $5.48^{*}$ \\
\hline Age (in years) & $21.54(1.51)$ & $21.28(1.62)$ & .26 \\
\hline Education level & & & $13.88^{* * *}$ \\
\hline$<$ High school & .41 & .11 & \\
\hline High school & .30 & .29 & \\
\hline Some college & .23 & .47 & \\
\hline College+ & .07 & .13 & \\
\hline Married & .25 & .13 & $6.03^{*}$ \\
\hline Employed full time & .51 & .46 & .40 \\
\hline Currently receiving welfare & .09 & .04 & 2.38 \\
\hline Placed in $1+$ foster homes & .40 & & \\
\hline Own residence & .00 & .10 & .01 \\
\hline Own car & .01 & .72 & .91 \\
\hline Bank account & .01 & .87 & $30.08^{* * *}$ \\
\hline \multicolumn{4}{|l|}{ Young-adult characteristics (Wave 1) } \\
\hline Mom receives welfare & .25 & .09 & $15.18^{* * *}$ \\
\hline Receive out-of-school suspension & .48 & .23 & $12.54^{* * *}$ \\
\hline Receive psychological counseling & .37 & .12 & $26.14^{* * *}$ \\
\hline Usually feel safe in neighborhood & .90 & .91 & .05 \\
\hline Mom cares about you very much & .90 & .98 & $9.56^{* *}$ \\
\hline Friends care about you very much & .90 & .87 & 1.03 \\
\hline \multicolumn{4}{|l|}{ NM relationship characteristics (Wave 3) } \\
\hline \# of NM functional roles & $1.37(.62)$ & $1.29(.61)$ & \\
\hline Guidance/advice & .56 & .60 & .35 \\
\hline Emotional nurturance & .56 & .40 & $5.04^{*}$ \\
\hline Practical help & .13 & .10 & .56 \\
\hline Like a parent & .01 & .05 & $4.64^{*}$ \\
\hline Role model & .08 & .15 & 1.51 \\
\hline Very close nm relationship & .01 & .54 & .93 \\
\hline Length of relationship (in yrs) & $10.54(7.89)$ & $8.94(7.07)$ & 1.28 \\
\hline NM became important early ( $0-17$ yrs $)$ & .83 & .78 & 67 \\
\hline NM's social role & & & .86 \\
\hline Relative & .54 & .45 & \\
\hline School personnel & .25 & .33 & \\
\hline
\end{tabular}




\begin{tabular}{|c|c|c|c|}
\hline Variable & Former foster youth $\% / M(S D)$ & Nonformer foster youth $\% / M(S D)$ & $\chi^{2} / t$ \\
\hline Community member & .21 & .22 & \\
\hline How nm was introduced & & & .82 \\
\hline Through family & .02 & .04 & \\
\hline Through a friend & .21 & .11 & \\
\hline Through school & .53 & .56 & \\
\hline Through work & .11 & .18 & \\
\hline Other & .13 & .10 & \\
\hline $\mathrm{NM}$ is still important to you & .97 & .92 & 1.07 \\
\hline See NM once/month or more & .55 & .51 & .23 \\
\hline Talk to/email NM once/month or more & .60 & .54 & .64 \\
\hline \multicolumn{4}{|l|}{${ }^{*} p<0.05}$. \\
\hline \multicolumn{4}{|l|}{$*^{* *} p<0.01}$. \\
\hline$* * * * 0.001$. & & & \\
\hline
\end{tabular}

